University of the Pacific

Scholarly Commons

3-11-2019

\title{
Rational Design of Peptide Ligands Based on Knob-Socket Protein Packing Model Using CD13 as a Prototype Receptor
}

\author{
Zahir Uddin \\ University of the Pacific \\ Xiaoling Li \\ University of the Pacific, xli@pacific.edu \\ Hyun Joo \\ University of the Pacific, hjoo@pacific.edu \\ Jerry Tsai \\ University of the Pacific, jtsai@pacific.edu \\ Lisa A. Wrischnik \\ University of the Pacific, Iwrischnik@pacific.edu
}

See next page for additional authors

Follow this and additional works at: https://scholarlycommons.pacific.edu/phs-facarticles

\author{
Recommended Citation \\ Uddin, Z., Li, X., Joo, H., Tsai, J., Wrischnik, L. A., \& Jasti, B. R. (2019). Rational Design of Peptide Ligands \\ Based on Knob-Socket Protein Packing Model Using CD13 as a Prototype Receptor. ACS Omega, 4(3), \\ 5126-5136. DOI: 10.1021/acsomega.8b03421 \\ https://scholarlycommons.pacific.edu/phs-facarticles/351
}

This Article is brought to you for free and open access by the Thomas J. Long School of Pharmacy at Scholarly Commons. It has been accepted for inclusion in School of Pharmacy Faculty Articles by an authorized administrator of Scholarly Commons. For more information, please contact mgibney@pacific.edu. 


\section{Authors}

Zahir Uddin, Xiaoling Li, Hyun Joo, Jerry Tsai, Lisa A. Wrischnik, and Bhaskara R. Jasti 


\title{
Rational Design of Peptide Ligands Based on Knob-Socket Protein Packing Model Using CD13 as a Prototype Receptor
}

\author{
Md Zahir Uddin, ${ }^{\dagger}$ Xiaoling Li, ${ }^{\dagger}$ Hyun Joo, Jerry Tsai, ${ }^{\ddagger}$ Lisa Wrischnik, ${ }^{\S}$ and Bhaskara Jasti* ${ }^{\dagger}{ }^{\dagger}$ \\ ${ }^{\dagger}$ Thomas J. Long School of Pharmacy, Department of Pharmaceutics and Medicinal Chemistry, University of the Pacific, 751 \\ Brookside Road, Stockton, California 95211, United States \\ ${ }^{\ddagger}$ Department of Chemistry and ${ }^{\S}$ Department of Biological Sciences, University of the Pacific, 3601 Pacific Avenue, Stockton, \\ California 95211, United States
}

Supporting Information

\begin{abstract}
Structure-based computational peptide design methods have gained significant interest in recent years owing to the availability of structural insights into protein-protein interactions obtained from the crystal structures. The majority of these approaches design new peptide ligands by connecting the crucial amino acid residues from the protein interface and are generally not based on any predicted receptor-ligand interaction. In this work, a peptide design method based on the Knob-Socket model was used to identify the specific ligand residues packed into the receptor interface. This method enables peptide ligands to be designed rationally by predicting amino acid residues that will fit best at the binding

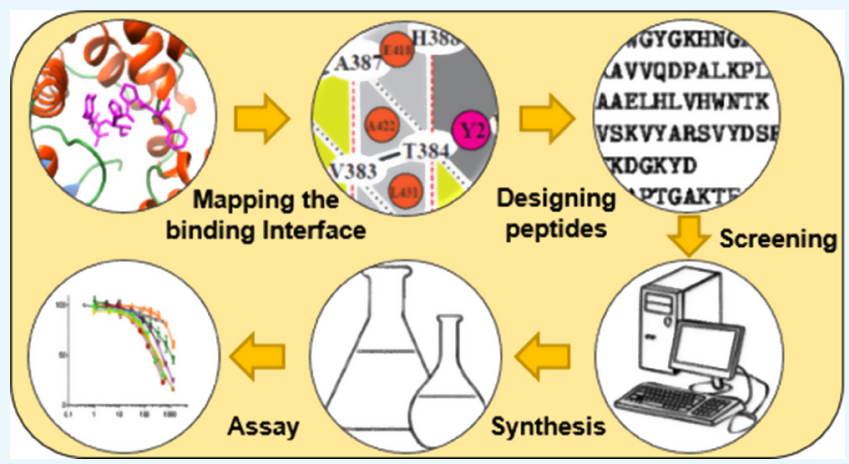
site of the receptor protein. In this, specific peptide ligands were designed for the model receptor CD13, overexpression of which has been observed in several cancer types. From the initial library of designed peptides, three potential candidates were selected based on simulated energies in the CD13 binding site using the programs molecular operating environment and AutoDock Vina. In the CD13 enzymatic activity inhibition assay, the three identified peptides exhibited 2.7-7.4 times lower $\mathrm{IC}_{50}$ values (GYPAY, $227 \mu \mathrm{M}$; GFPAY, $463 \mu \mathrm{M}$; GYPAVYLF, $170 \mu \mathrm{M}$ ) as compared to the known peptide ligand CNGRC $(\mathrm{C} 1-\mathrm{C} 5)(1260 \mu \mathrm{M})$. The apparent binding affinities of the peptides (GYPAY, $K_{\mathrm{i}}=54.0 \mu \mathrm{M}$; GFPAY, $K_{\mathrm{i}}=74.3 \mu \mathrm{M}$; GYPAVYLF, $K_{\mathrm{i}}=38.8 \mu \mathrm{M}$ ) were $10-20$ times higher than that of CNGRC (C1-C5) $\left(K_{\mathrm{i}}=773 \mu \mathrm{M}\right)$. The double reciprocal plots from the steady-state enzyme kinetic assays confirmed the binding of the peptides to the intended active site of CD13. The cell binding and confocal microscopy assays showed that the designed peptides selectively bind to the CD13 on the cell surface. Our study demonstrates the feasibility of a Knob-Socket-based rational design of novel peptide ligands in improving the identification of specific binding versus current more labor-intensive methods.
\end{abstract}

\section{INTRODUCTION}

The world of medicine is moving fast toward precision and personalized care where drugs are being tailored according to individual variability and delivered specifically to the diseased tissue. ${ }^{1}$ One of the most popular strategies to enhance the therapeutic efficacy while minimizing the systemic toxicities has been the active drug targeting with the aid of specially designed ligand moieties. ${ }^{2-4}$

Antibodies, peptides, and aptamers are some of the commonly used targeting molecules. Among these, peptides possess several attractive features such as high target specificity, reduced likelihood of unintended immunogenic interactions, and smaller size leading to better tissue penetration and favorable pharmacokinetic properties. ${ }^{5,6}$ There are more than 60 peptide drug products approved by US Food and Drug Administration, with additional 140 peptide drugs in clinical trials and more than 500 therapeutic peptides in preclinical stage. ${ }^{7}$ Recent advancements in robust chemical synthesis and conjugation techniques are expected to further increase the use of peptide-based molecules in diagnosis, imaging, and therapy.

The efficient design of high-affinity peptide ligands via rational methods has been a major obstacle to the development of this potential drug class. ${ }^{8}$ The most widely adopted strategy to identify a new peptide ligand is phage display, where a large library of peptides is screened against a predetermined target. $^{9-11}$ This high throughput technique has been a powerful and versatile approach for peptide ligand identification, but it is inherently time consuming and resource demanding. One relatively new peptide design methodology, the computational design method combines structural information with docking, to develop new peptides. ${ }^{8}$ Campa et al. ${ }^{12}$ reported the design of a novel type III epidermal

Received: December 5, 2018

Accepted: February 26, 2019

Published: March 11, 2019 
growth factor receptor (EGFRvIII) binding peptide through hydropathic complementarity approach. Using the program ANIMOMAT, the peptide sequences were designed to bind EGFRvIII. In 2000, Park et al. ${ }^{13}$ published a study on the design of a peptidomimetic having comparable biological properties to those of an antibody. This peptidomimetic was developed based on an analysis of the human epidermal growth factor receptor 2 (HER2/neu)-antibody (anti-HER2/ neu) co-crystal structure. In another computer-assisted in silico screening of a large virtual library of peptides by Song et al., ${ }^{14}$ they selected a peptide ligand for EGFR binding. Generally, peptides derived from an analysis of the protein interface structure constitute the primary source of these designs. ${ }^{8}$ However, none of them identify peptide ligands using a model that exactly defines the specific packing of the ligand residues within a structure's binding interface. Therefore, a rational peptide design technique based on the clear mapping of amino acid side-chain packing arrangements between ligand and target proteins has distinct advantages. In this regard, the Knob-Socket (KS) based approach could help to reduce the development time by allowing rational and expeditious inprocess optimization and provides plausible alternatives to the experimental high-resolution receptor protein-peptide complex structures.

In this study, a rational peptide design method is investigated that clearly defines the packing of the ligand at the binding site of the receptor protein. The method is based on a novel description of protein-packing known as KS that provides a simplified yet accurate representation of residue packing between two molecules. ${ }^{15-17}$ The KS model uses the precision of Voronoi polyhedra/Delaunay tessellations to identify contacts ${ }^{18,19}$ and is described as a 4-residue tetrahedral motif, where a one-residue knob belonging to a secondary structure packs into a three-residue socket on another secondary structure. The KS model also provides information about the propensities of the knobs that most likely can pack into a respective socket.

We employed this rational method to design peptide ligands for a prototype target-tumor vascular endothelial cluster of differentiation 13 (CD13) receptor. The CD13, also known as aminopeptidase $\mathrm{N}$, is a 967-residue type-2 cell surface membrane glycoprotein. It is one of the tumor vasculature biomarkers associated with several of the malignant phenotypes such as cell proliferation, secretion, invasion, and angiogenesis. CD13 is overexpressed in many cancers such as breast, kidney, prostate, ovarian, colon, gastric, pancreatic, and thyroid cancer. ${ }^{20-25}$

CD13 is a good prototype target for the present study because it has an established peptide ligand CNGRC (C1C5), identified through a phage display study, which can serve as a direct comparison for the evaluation of designed peptides. Additionally, this target allows a clean in vivo evaluation of the designed peptides as the endothelial cells of the tumor vasculature are readily accessible to the ligands, and the vascular endothelial cells are genetically more stable than the tumor cells in developing drug resistance. ${ }^{26,27}$

\section{METHODS}

Peptide Design. Confirming the Peptide Binding Site on Human CD13 (hCD13). The crystal structure of porcine CD13 (pCD13) is available in a complex with a peptide targeting ligand CNGRCG ( $\mathrm{C} 1-\mathrm{C} 5)$ [protein data bank (PDB) ID: 4OU3]. ${ }^{28}$ However, the crystal structure of human CD13
(hCD13) is only available in a complex with the endogenous ligand ANG IV (PDB ID: 4FYS). ${ }^{29}$ To confirm the target site for the peptide ligand, PDB ID: 4FYS and PDB ID: 4OU3 were loaded in molecular operating environment (MOE) software (version 2013.08, Chemical Computing Group, Montreal, QC, Canada) with a solution phase AMBER10:EHT forcefield and R-field solvation model. Nonbinding portions of the protein structures were then deleted keeping only the binding site residues. For hCD13, the amino acids are A191A215, K340-L487, and R855-R908, and for pCD13, they are A186-T210, K335-L482, and R852-R905. The homology between the hCD13 and pCD13 binding sites was analyzed using the Align and Superpose functions in the MOE.

Mapping the hCD13-ANG IV Binding Interface. The PDB file of the hCD13-ANG IV complex (PDB ID: 4FYS) was loaded in the University of California, San Francisco (UCSF) Chimera program package. $^{30}$ The program connected the sequences of hCD13 and ANG IV together and renumbered all the amino acids for the whole complex. (Dictionary of secondary structure of proteins) program ${ }^{31}$ was used to assign the secondary structure definition to the hCD13. An in-house program named relative packing clique was used to precisely define a set of all residues that contact each other and classify them based on contact order. ${ }^{32}$ Contacts were calculated from a Voronoi polyhedra analysis ${ }^{18}$ which included side-chain-toside-chain contacts and side-chain-to-main-chain contacts for all the residues. In addition, contacts were considered for mainchain-to-main-chain contacts for all nonneighboring residues. The resulting Delaunay tessellation defines a contact graph between residues. ${ }^{19}$ On the basis of the calculated twodimensional contact graph, all sockets and knobs formed on the binding interface were identified.

Designing Peptide Ligands. The sockets on the protein that took part in ligand binding along with some other free sockets were selected as the target site for the peptide ligands. Peptides were then designed by selecting the amino acid residues having highest (or second highest) propensities toward the selected sockets on the target site (Table S1). ${ }^{33}$ When the distance between two knob residues was far because of the physical separation between the two CD13 surface sockets, flanking amino acids were inserted to fill the gap. A database of five amino acid (5-mer) long peptides was created using different combinations of amino acids from the list of highest (or second highest) propensity knobs. A second database of eight amino acid (8-mer) long peptides was also created using the same method to cover larger binding surface.

Screening of the Peptide Ligands. Peptide sequences were first screened from the initial database using the following predetermined criteria. Peptides that have glutamine at the $\mathrm{N}$ terminal can easily condense to form pyroglutamate degradation products. ${ }^{34}$ Peptides with Xaa-proline residues at the $\mathrm{N}$ terminal may lead to diketopiperazine formation, ${ }^{35}$ and oxidation of methionine produces sulfoxide amino acids. ${ }^{36}$ Consequently, peptides with glutamine or Xaa-proline on the $\mathrm{N}$-terminal or methionine in the sequence were discarded. Additionally, peptides containing same amino acids consecutively were also removed from the initial database. The remaining peptides were constructed in MOE using the Molecule Builder tool, and energy minimization was performed using the AMBER10:EHT forcefield and R-field solvation model. After loading the hCD13-ANG IV complex (PDB ID: 4FYS) in MOE, the protein structure was prepared using the LigX function with the default setting except the 
receptor strength of 5000. The glycan, solvent, and buffer molecules as well as the endogenous ligand ANG IV were removed from the docking simulation. Because the peptide design approach is based on the KS protein packing and the model does not take water-mediated intermolecular interactions in to account, the solvent molecules were removed from the hCD13 crystal structure. Docking of the peptides was performed on the hCD13's peptide binding site using Dock function with a rigid receptor protocol. As opposed to induced fit protocol which allows flexible side chains, in the rigid receptor protocol side chains of the receptor are held fixed. The rigid receptor protocol was used in the study as the induced fit protocol requires significantly longer docking time and higher computational power. Timeout (seconds) and no. of return poses in the default triangle matcher placement option of the docking window were configured to 500 and 2000 , respectively. At the end of docking, MOE produced 100 possible conformations for each peptide and respective docking score for the complex of peptides and hCD13. Potential peptide candidates were selected using the docking score from MOE. The docking score function estimates the free energy of binding of the ligand from a given binding pose. A low (negative) docking score indicates a stable system and thus a likely interaction between the receptor and ligand. Further docking studies were performed using a second molecular modeling software-AutoDock Vina. ${ }^{37}$ The hCD13 structure (PDB ID: 4FYS) was prepared using Dock Prep in UCSF Chimera. The endogenous ligand ANG IV, glycans, buffer, and water molecules were removed. The designed peptide structures along with the positive control CNGRC (C1-C5) peptide were generated in Chimera using Build Structure function with default settings. The peptide structures were then prepared using Dock Prep and Minimize Structure functions. AutoDock Tools within MGLTools (version 1.5.6) were used to generate the PDBQT format files of the peptides and receptor. The docking was performed using the methods described by Hauser and Windshüge ${ }^{38}$ and in AutoDock Vina manual. $^{39}$ The position of the grid box center was set at $(x, y$, $z)=(101.98,20.068,18.861)$, and the $x y z$ dimensions of the grid box were 80, 62, and $62 \AA$, respectively. The exhaustiveness of the docking run was set at 100. A small set of peptides was selected for further experimental evaluation based on the AutoDock Vina predicted binding sites.

Peptide Synthesis and Characterization. The selected designed peptides, CNGRC (C1-C5) peptide (NGR-2C), and GARAG peptide (negative control), were synthesized by the standard solid-phase synthesis method. ${ }^{40-44}$ The amino acids and coupling reagents were obtained from Chem-Impex (Wood Dale, IL, USA). Coupling of subsequent amino acids was performed with 1-hydroxy-benzotriazole and diisopropylcarbodiimide. In case of the CNGRC $(\mathrm{C} 1-\mathrm{C} 5)$ peptide, the synthesis scheme started with Fmoc-L-Cys(Trt)-2-chlorotrityl resin and cyclization was achieved by the formation of $1-5$ disulfide bond using iodine in dimethylformamide (DMF) at 0 ${ }^{\circ} \mathrm{C}$ for $2 \mathrm{~h}^{45}$ In case of fluorescein isothiocyanate (FITC) conjugated peptides, the synthesis was started with FmocLys(ivDde)-Wang resin (Peptides International, Louisville, KY, USA) to maintain simple solid phase synthesis method and easily place the probe toward C-terminal side. ${ }^{46}$ A linker (e.g. 6-aminohexanoic acid/Ahx) was added between the peptide sequence and the lysine residue at the C-terminal. After coupling the last Boc-protected amino acid at the N-terminal, the resins were treated with $2 \%$ hydrazine to remove the ivDde group from the C-terminal lysine. Then FITC (AnaSpec, Fremont, CA, USA) was coupled to the exposed primary $-\mathrm{NH}_{2}$ group on the side chain of lysine. ${ }^{47}$ Finally, the FITClabeled peptides were cleaved from the resin using trifluoroacetic acid-water-triisopropylsilane (95:2.5:2.5) cocktail. After synthesis, both unconjugated and FITC-conjugated peptides were freeze-dried and purified using reversed phase high-performance liquid chromatography (RP-HPLC). An Agilent Zorbax C18, $5 \mu$, 4.6 × 150 mm (Agilent Technologies, Santa Clara, CA, USA) column was used, and the eluents were detected at 210, 254, and $280 \mathrm{~nm}$. Water with $0.1 \%$ trifluoroacetyl (TFA) (A) and acetonitrile with $0.1 \%$ TFA (B) were used as mobile phase and eluted using a linear gradient from 10 to $90 \% \mathrm{~B}$ over $30-35 \mathrm{~min}$ at $1.0 \mathrm{~mL} / \mathrm{min}$ flow rate. After purification, each product was found to have more than $92 \%$ purity according as shown Table S2. Electronspray ionization mass spectrometry analysis confirmed the formation of each molecule (Table S2).

CD13 Catalysis Inhibition Assay. For the CD13 catalysis inhibition assay, ${ }^{28,48-50}$ His-tagged human CD13 protein (Sino Biological, Beijing, China) at $2 \mathrm{nM}$ and $172 \mu \mathrm{M} \mathrm{L}-$ alanine 7-amido-4-methylcoumarin (Ala-MCA) (Santa Cruz Biotechnology, Dallas, TX, USA) were incubated in 96-well polystyrene microplates with $100 \mu \mathrm{L}$ of binding buffer/well [10 mM HEPES and $0.1 \% \mathrm{w} / \mathrm{v}$ bovine serum albumin (BSA) in phosphate-buffered saline (PBS), $\mathrm{pH}$ 7.2] with gradient concentrations of the peptides at $37{ }^{\circ} \mathrm{C}$. The release of fluorescent product 7-amido-4-methylcoumarin was measured using a BioTek Synergy HT microplate reader (BioTek Instruments, Winooski, VT, USA) at $\lambda_{\mathrm{exc}}$ of $360 \mathrm{~nm}$ and $\lambda_{\mathrm{em}}$ of $460 \mathrm{~nm}$. The $\mathrm{IC}_{50}$ is defined as the concentration of the peptide causing 50\% inhibition of the CD13 enzymatic activity. The steady-state enzyme kinetic assays were performed at room temperature as described above, using incremental concentrations of Ala-MCA $(33-526 \mu \mathrm{M})$, at fixed concentrations of the peptides ranging from 0 to $1304 \mu \mathrm{M}$. Initial rates $\left(V_{0}\right)$ were calculated from the slopes of the first $5 \mathrm{~min}$ of the reaction. The inhibitory constants $\left(K_{\mathrm{i}}\right)$ were calculated using either competitive or noncompetitive enzyme inhibition model in GraphPad Prism 7 (La Jolla, CA, USA).

Evaluation of CD13 Expression Levels in Selected Cell Lines. Western blot studies were carried out to detect the CD13 expression levels in HT-1080 and MCF-7 cells. The cells (ATCC, Manassas, VA, USA) were lysed with cell lysis buffer (Cell Signaling, Boston, MA, USA) and protein concentrations were determined by the bicinchoninic acid assay (BCA assay). Cell proteins $(20 \mu \mathrm{g})$ were then loaded into wells on sodium dodecyl sulfate-polyacrylamide gel electrophoresis (SDS-PAGE gel, Bio Rad, Hercules, CA, USA). The proteins on gel was then transferred to the 0.45 $\mu \mathrm{m}$ nitrocellulose membrane (Bio Rad, Hercules, CA, USA), blocked for $1 \mathrm{~h}$ with $5 \% \mathrm{w} / \mathrm{v}$ BSA in $0.1 \%$ Tween 20 Trisbuffered saline and then incubated overnight at $4{ }^{\circ} \mathrm{C}$ with a primary antibody (anti-CD13 antibody [EPR4058], Abcam, Cambridge, MA, USA). The membrane was incubated with a secondary antibody (donkey anti-rabbit IgG IRDye 800CW, 1:10 000) (LI-COR, Lincoln, NE, USA) in the blocking buffer for $1 \mathrm{~h}$ at room temperature. The membrane was scanned using a LI-COR Odyssey imaging system (Lincoln, NE, USA). To normalize the protein loading, the blots were incubated with $\beta$-actin (Cell Signaling, Boston, MA, USA) as a control.

Cell Surface CD13 Binding of the Peptides. For the cell surface CD13 binding assay, ${ }^{50} \mathrm{CD} 13$ positive HT-1080 cells 
and CD13 negative MCF-7 cells were seeded at $3-4 \times 10^{4}$ cells/well, $48 \mathrm{~h}$ before the experiment in 96-well clear-bottom black plates. On the day of experiment, the cells were washed twice with binding buffer before incubating $30 \mathrm{~min}\left(37^{\circ} \mathrm{C}, 5 \%\right.$ $\left.\mathrm{CO}_{2}\right)$ with each peptide conjugate $(60 \mu \mathrm{M})$ in the binding buffer. The cells were then fixed with $4 \%$ paraformaldehyde in PBS for $10 \mathrm{~min}$. The fluorescence intensities were measured using the BioTek Synergy HT microplate reader with FITC filter set. The cells were then counterstained with the nuclear stain Hoechst 33342 and analyzed using the same microplate reader with a DAPI filter set. Between each step, the cells were washed twice with the binding buffer.

Confocal Microscopy. HT-1080 and MCF-7 cells were seeded on to coverslips placed inside 6-well culture plates at a density of 100000 cells/well. The cells were allowed to attach for $24 \mathrm{~h}$ before the experiment was performed. The cells were incubated with FITC-conjugated peptides at a concentration of $30 \mu \mathrm{M}$ at $37{ }^{\circ} \mathrm{C}, 5 \% \mathrm{CO}_{2}$ for $20 \mathrm{~min}$ in binding buffer. Cells were then stained with Alexa Fluor 594 (plasma membrane dye) (Invitrogen), fixed with $4 \%$ paraformaldehyde in PBS, and visualized under a Leica DMIRE2 confocal laser scanning microscope (Leica Microsystems GmbH, Germany) at 63× magnification with oil immersion. Between each step, the cells were washed twice with the binding buffer.

\section{RESULTS}

Peptide Design. Porcine CD13 (pCD12) and human CD13 (hCD13) have high similarity of sequence ( $80 \%$ overall, $100 \%$ in the active site, $94 \%$ in the peptide-binding region). ${ }^{51}$ When the peptide-binding regions of hCD13 and pCD13 were aligned and superposed using MOE, the overall root-meansquare deviation was $0.833 \AA$, indicative of significant similarity in their binding site conformation (Figure 1). The endogenous

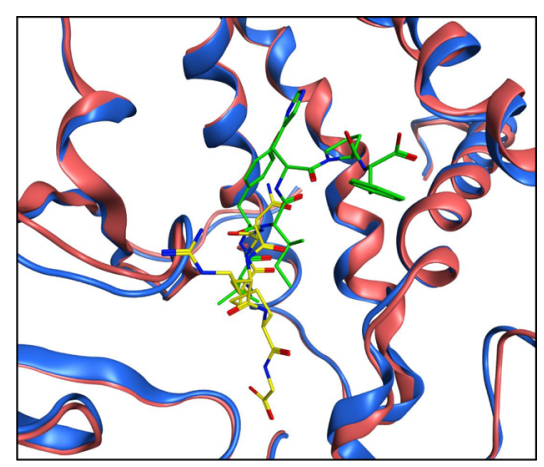

Figure 1. Binding sites of hCD13 and $\mathrm{pCD} 13$ aligned and superposed [blue structure- $\mathrm{hCD} 13$, green coil-ANG IV, magenta structurepCD13, yellow coil-CNGRCG $(\mathrm{C} 1-\mathrm{C} 5)]$.

ligand ANG IV and the peptide ligand CNGRCG (C1-C5) were also observed to reside very close to each other (Figure 1). This suggested that the location where ANG IV binds on hCD13 could be used as the target site for designing novel peptide ligands.

Using the KS model, ${ }^{15-17}$ the complicated CD13 ligand binding interface (Figure 2A) can be simplified and made more intelligible by the two-dimensional map of quaternary packing interactions shown in Figure 2B. A clear picture of the peptide residue knobs from ANG IV packing into sockets on the hCD13 surface is represented. There are nine sockets on hCD13 filled by the knob residues coming from ANG IV.
ANG IV also forms five sockets, which pack knobs from hCD13. For the 5-mer peptide design, six out of the nine sockets and one additional free socket formed by residues $441 \mathrm{Y}, 442 \mathrm{R}$, and $445 \mathrm{~A}$ were selected as the target site surface for the designed peptides (Figure 2C). For the designed peptide ligand, positions 1,2 , and 5 were chosen as knobs to pack into the binding sockets. At position 1, knobs were chosen for 2 binding sites: one consisting of two sockets in the helix and another consisting of a socket from a coil region. Position 2's knob only comes from the helix, whereas position 5 's knob is a single socket, but at 2 possible positions. Knobs with high propensities to interact with these sockets were chosen as the basis for the peptide sequences. Because these sockets span between two types of secondary structure that are $12 \AA$ apart at closest approach, two residues (positions 3 and 4 on the peptide) were necessary to bridge between the binding sites.

All possible combinations of the highest propensity knobs (Figure 2C inset table) produced 32 5-mer peptide sequences. Using the predetermined criteria (previously discussed in the Methods section), eight 5-mer peptides were selected from the initial sequences and subjected to MOE docking. These eight 5-mer peptides were ranked according to their MOE docking scores (Table 1). In case of 8 -mer peptide design, a total of 384 peptides were obtained using all possible combinations of the knobs (Figure 2D inset table) that subsequently led to 40 8-mer peptide sequences after applying the predetermined criteria. These 40 peptides were subjected to MOE docking and the top 10 ranking peptides (top $25 \%$ based on the MOE docking score) are listed in Table 1 .

Additional docking studies with AutoDock Vina were performed for all eight of the 5-mer peptides and top 25\% (10) of the 8-mer peptides based on MOE docking score ranking. Of these, AutoDock Vina predicted that three designed peptides [two 5-mer (PEP20, GYPAY, and PEP24, GFPAY), and one 8-mer (PEP173, GYPAVYLF)] could bind to the intended active site of hCD13 similar to the positive control CNGRC (C1-C5) peptide ligand (NGR-2C) (Figure 3 and Table 1). These three peptides along with two other nonspecific peptides (PEP293, GYPAYVEF and PEP308, GFPAVYEF; as negative controls) were selected for experimental evaluation.

Characterization of CD13 Binding Properties of the Peptides. The enzyme inhibition assays were performed to characterize the apparent affinities of the peptides toward CD13. The designed peptides inhibited the CD13 catalyzed hydrolysis of Ala-MCA substrate, at significantly lower concentrations than NGR-2C peptide (Figure 4A and Table 2 ). The illustrated curve-fittings are based on single inhibitor binding site. $\mathrm{IC}_{50}$ values observed for the designed peptides were 2.7-7.4 times lower than that of NGR-2C (Table 2). To gain insights into the mode of inhibition of the peptide ligands, steady-state enzyme kinetic assays (Figure 4B and Table 2) were performed at room temperature. The Lineweaver-Burk double reciprocal plots for PEP20, PEP24, PEP173, and NGR$2 \mathrm{C}$ showed a series of lines crossing the $y$-axis $\left(1 / V_{0}\right)$ at the same point-that is, $V_{\max }$ unchanged, but with increasing values of Michaelis constant $\left(K_{\mathrm{m}}\right)$. These data were consistent with competitive inhibition model (PEP20, $K_{\mathrm{i}}=54.0 \pm 11.9$ $\mu \mathrm{M}$; PEP24, $K_{\mathrm{i}}=74.3 \pm 12.0 \mu \mathrm{M}$; PEP173, $K_{\mathrm{i}}=38.8 \pm 5.21$ $\mu \mathrm{M}$; NGR-2C, $\left.K_{\mathrm{i}}=773 \pm 157 \mu \mathrm{M}\right)$, suggesting that PEP20, PEP24, PEP173, and NGR-2C bind to the catalytic site of CD13. On the other hand, PEP293 and PEP308 were found to 


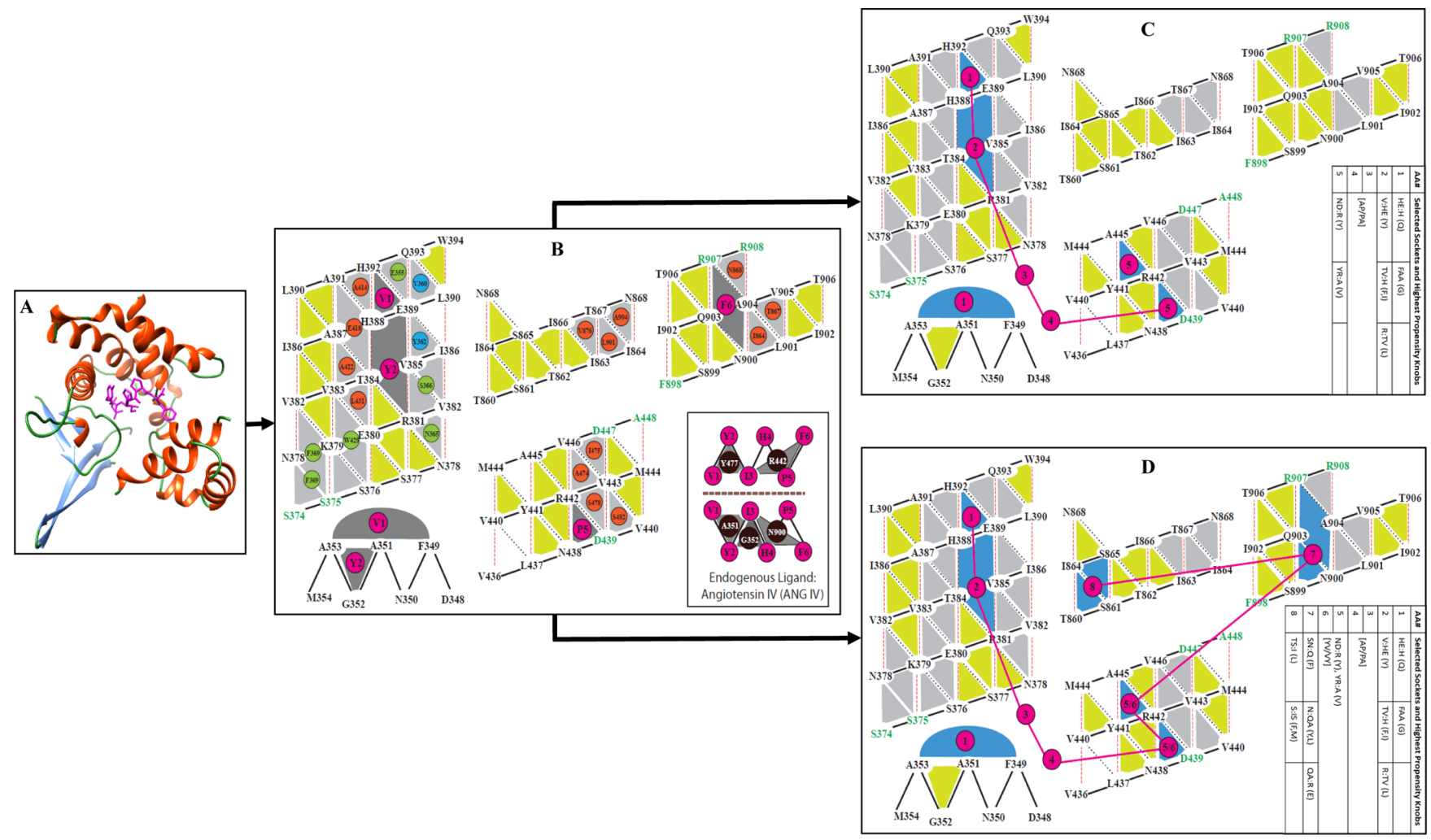

Figure 2. (A) Binding site of hCD13 with the endogenous ligand ANG IV (magenta coil), (B) 2D lattice diagram of the binding interface between hCD13 and ANG IV, (C) peptide design for the 5-mer, and (D) peptide design for the 8-mer. Sockets are represented by triangles or half-ellipses, while residue knobs are shown as circles. Gray- and yellow-shaded sockets are the filled and empty sockets on hCD13, respectively. Blue-shaded sockets are the hCD13 sockets used to select high propensity knobs for the peptide design. Knobs are colored based on their origin. Knobs involved in tertiary structure packing within hCD13 are colored green from coil, red from helix, and blue from sheet. Knobs involved in quaternary binding of the peptide ligand are colored magenta. Likewise, the knobs used in the peptide design are also colored magenta. Black circles represent the knobs coming from the receptor which pack against sockets formed by endogenous/designed peptide ligand. In (C,D), receptor knobs were omitted, and the inset table lists the high propensity knobs at each position.

\section{Table 1. Designed Peptides with Docking Results}

\begin{tabular}{|c|c|c|c|c|c|c|c|c|c|c|c|}
\hline & Residue $\rightarrow$ & & & & & & & & & & \\
\hline Ranking & Peptide $\downarrow$ & 1 & 2 & 3 & 4 & 5 & 6 & 7 & 8 & MOE Docking Score & autoDock Vina predicted binding site \\
\hline \multicolumn{12}{|c|}{ 5-mer peptides } \\
\hline 1 & 20 & G & $\mathrm{Y}$ & $\mathrm{P}$ & A & $\mathrm{Y}$ & & & & -13.9095 & on active site \\
\hline 2 & 24 & G & $\mathrm{F}$ & $P$ & A & $\mathrm{Y}$ & & & & -11.9234 & on active site \\
\hline 3 & 19 & G & $\mathrm{Y}$ & $\mathrm{P}$ & A & $\mathrm{V}$ & & & & -11.7211 & distant from active site \\
\hline 4 & 27 & G & I & $\mathrm{P}$ & A & $\mathrm{V}$ & & & & -11.6586 & distant from active site \\
\hline 5 & 32 & G & $\mathrm{L}$ & $\mathrm{P}$ & A & $\mathrm{Y}$ & & & & -11.5135 & distant from active site \\
\hline 6 & 28 & G & I & $\mathrm{P}$ & A & $\mathrm{Y}$ & & & & -11.3576 & distant from active site \\
\hline 7 & 31 & G & $\mathrm{L}$ & $\mathrm{P}$ & A & $\mathrm{V}$ & & & & -10.7643 & distant from active site \\
\hline \multirow[t]{2}{*}{8} & 23 & G & $\mathrm{F}$ & $\mathrm{P}$ & A & $\mathrm{V}$ & & & & -10.7205 & distant from active site \\
\hline & NGR-2C & $\mathrm{C}$ & $\mathrm{N}$ & G & $\mathrm{R}$ & $C(1-5)$ & & & & -11.2815 & on active site \\
\hline \multicolumn{12}{|c|}{ 8-mer peptides } \\
\hline 1 & 296 & G & $\mathrm{Y}$ & $\mathrm{P}$ & A & $\mathrm{V}$ & $\mathrm{Y}$ & $\mathrm{E}$ & $\mathrm{F}$ & -16.9475 & distant from active site \\
\hline 2 & 293 & G & $\mathrm{Y}$ & $\mathrm{P}$ & A & $\mathrm{Y}$ & $\mathrm{V}$ & $\mathrm{E}$ & $\mathrm{F}$ & -16.6503 & distant from active site \\
\hline 3 & 317 & G & I & $\mathrm{P}$ & A & $\mathrm{Y}$ & $\mathrm{V}$ & $\mathrm{E}$ & $\mathrm{F}$ & -16.6490 & distant from active site \\
\hline 4 & 389 & G & $\mathrm{L}$ & $\mathrm{P}$ & A & $\mathrm{Y}$ & $\mathrm{V}$ & $\mathrm{Y}$ & $\mathrm{F}$ & -16.5394 & distant from active site \\
\hline 5 & 209 & G & $\mathrm{F}$ & $\mathrm{P}$ & A & $\mathrm{V}$ & $\mathrm{Y}$ & $\mathrm{L}$ & $\mathrm{F}$ & -16.4622 & distant from active site \\
\hline 6 & 161 & G & $\mathrm{Y}$ & $\mathrm{P}$ & A & $\mathrm{Y}$ & $\mathrm{V}$ & $\mathrm{Y}$ & $\mathrm{F}$ & -16.3548 & distant from active site \\
\hline 7 & 308 & G & $\mathrm{F}$ & $\mathrm{P}$ & A & $\mathrm{V}$ & $\mathrm{Y}$ & $\mathrm{E}$ & $\mathrm{F}$ & -16.2962 & distant from active site \\
\hline 8 & 173 & G & $\mathrm{Y}$ & $\mathrm{P}$ & A & $\mathrm{V}$ & $\mathrm{Y}$ & $\mathrm{L}$ & $\mathrm{F}$ & -16.2385 & on active site \\
\hline 9 & 387 & G & $\mathrm{L}$ & $P$ & A & $\mathrm{Y}$ & $\mathrm{V}$ & $\mathrm{Y}$ & $\mathrm{L}$ & -16.0129 & distant from active site \\
\hline 10 & 245 & G & I & $\mathrm{P}$ & A & $\mathrm{V}$ & $\mathrm{Y}$ & $\mathrm{L}$ & $\mathrm{F}$ & -15.8007 & distant from active site \\
\hline
\end{tabular}




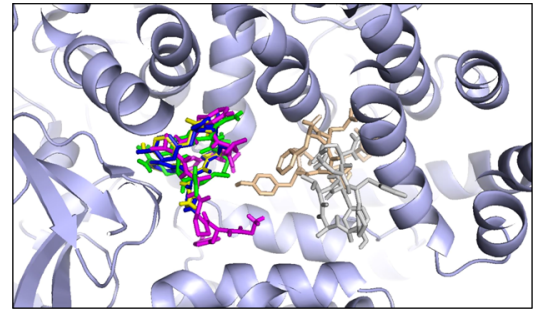

Figure 3. Peptides (coil structures) at hCD13 binding site after docking with AutoDock Vina. Green: NGR-2C, blue: PEP20, yellow: PEP24, magenta: PEP173, wheat: PEP293, gray: PEP308. lower the $V_{\max }$, without affecting $K_{\mathrm{m}}$ (Figure 4B), suggesting that they can bind to CD13 in the presence of a substrate. This indicates noncompetitive inhibition mode of PEP293 and PEP308. The values of the kinetic parameters (global $V_{\max }$ and $K_{\mathrm{m}}$ ) are listed in Table S3. The similarity between the experimental and simulated binding characteristics of the peptides is explained later (see discussion, Tables 1 and 2, and Figures 3 and 4).

CD13 Expression Levels in Selected Cell Lines. In the western blot studies, while HT-1080 cells exhibited clear CD13 bands, MCF-7 cells did not show significantly identifiable band of $\mathrm{CD} 13$ in the blots (Figure 5A). On the basis of the band

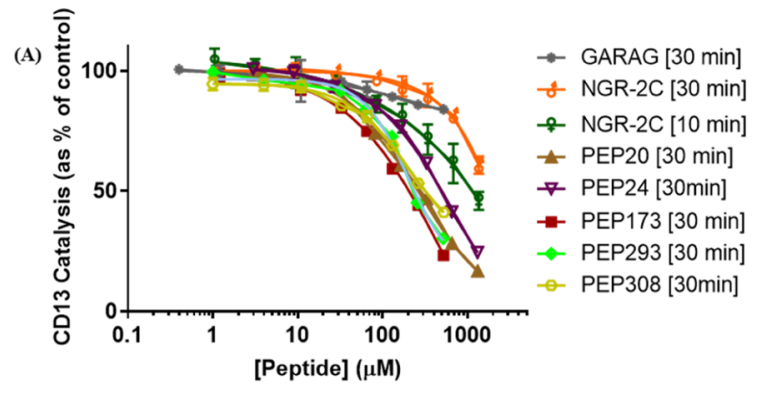

PEP20
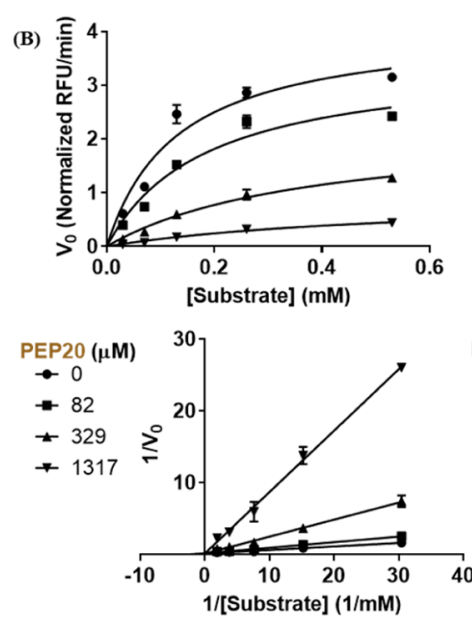

NGR-2C
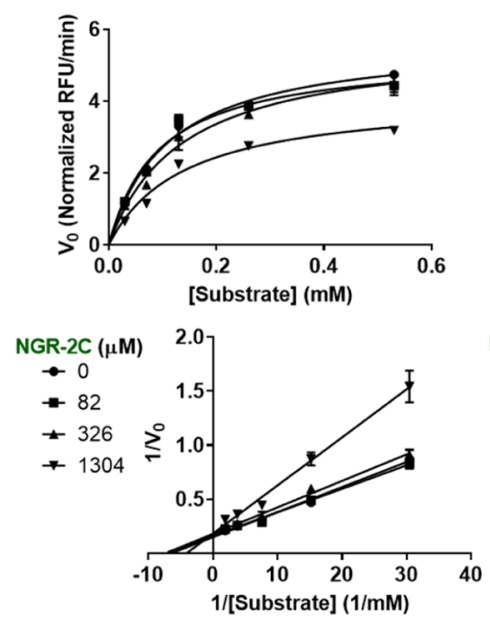

PEP24
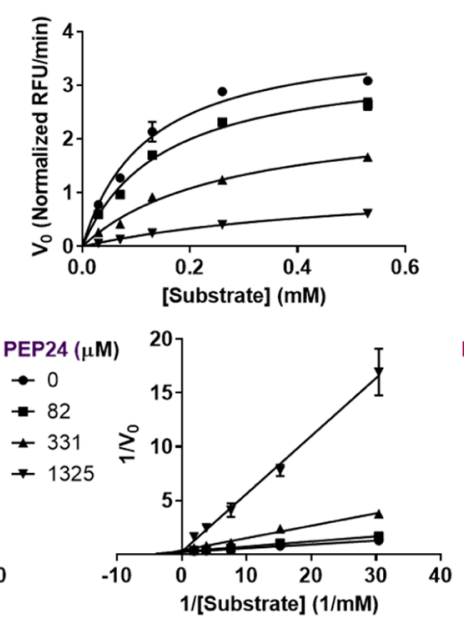

PEP293
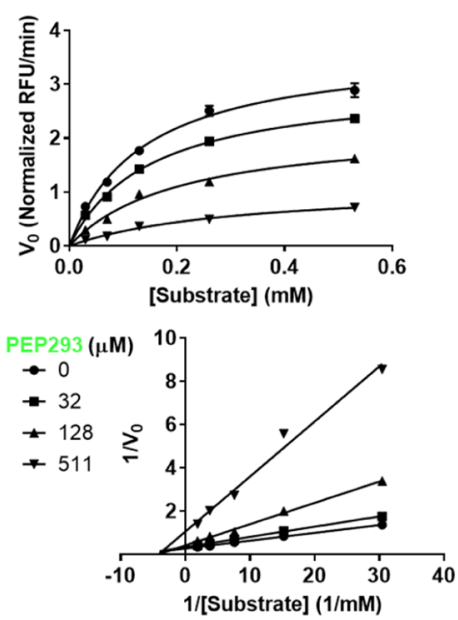

PEP173
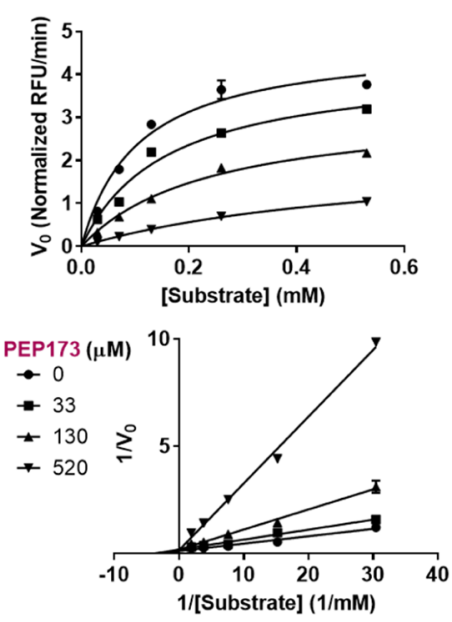

PEP308
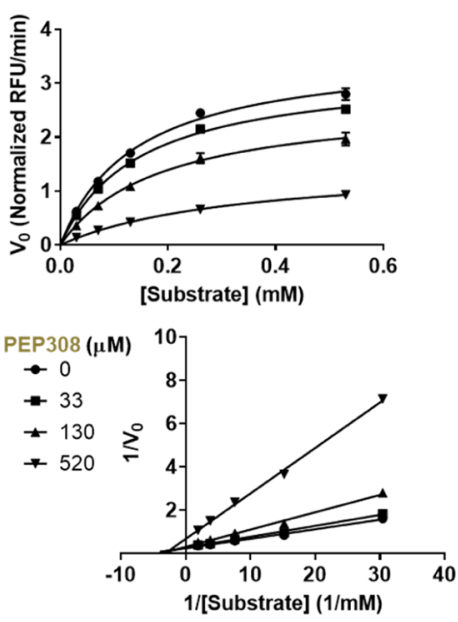

Figure 4. Effect of different peptides on CD13 enzymatic activity. (A) CD13 catalysis inhibition by the peptides $(n=3$, mean \pm SE in duplicate or triplicate). (B) Steady-state kinetic analysis of CD13 in the presence of the Ala-MCA substrate and different peptide inhibitors; plots of initial velocity $\left(V_{0}\right)$ vs Ala-MCA concentration (upper panels) and double reciprocal plots (lower panels) (mean \pm SE, in triplicate). 
Table 2. CD13 Catalysis Inhibition Assay Data

\begin{tabular}{llrcr}
\multicolumn{1}{c}{ peptides } & \multicolumn{1}{c}{ sequence } & $\mathrm{IC}_{50}(\mu \mathrm{M})^{a, b}$ & binding affinity, $K_{\mathrm{i}}(\mu \mathrm{M})^{c, d}$ & inhibition mode as determined from double reciprocal plots \\
PEP20 & GYPAY & $227 \pm 6.67$ & $54.0 \pm 11.9$ & competitive \\
PEP24 & GFPAY & $463 \pm 21.8$ & $74.3 \pm 12.0$ & competitive \\
PEP173 & GYPAVYLF & $170 \pm 23.0$ & $38.8 \pm 5.21$ & competitive \\
NGR-2C (+ve control) & CNGRC (C1-C5) & $1260 \pm 80.0$ & $773 \pm 157$ & competitive \\
GARAG (-ve control) & GARAG & & & noncompetitive \\
PEP293 & GYPAYVEF & $213 \pm 6.67$ & $137 \pm 8.31$ & noncompetitive \\
PEP308 & GFPAVYEF & $300 \pm 40.0$ & $234 \pm 14.3$ &
\end{tabular}

$a_{n=3}$, mean \pm SE. ${ }^{b}$ All after 30 min except NGR-2C after 10 min. ${ }^{c}$ Mean \pm SE. ${ }^{d}$ Competitive inhibition model was used in Prism 7 to determine the $K_{\mathrm{i}}$ for PEP20, 24, 173, and NGR-2C, whereas noncompetitive inhibition model was used for PEP293 and 308.
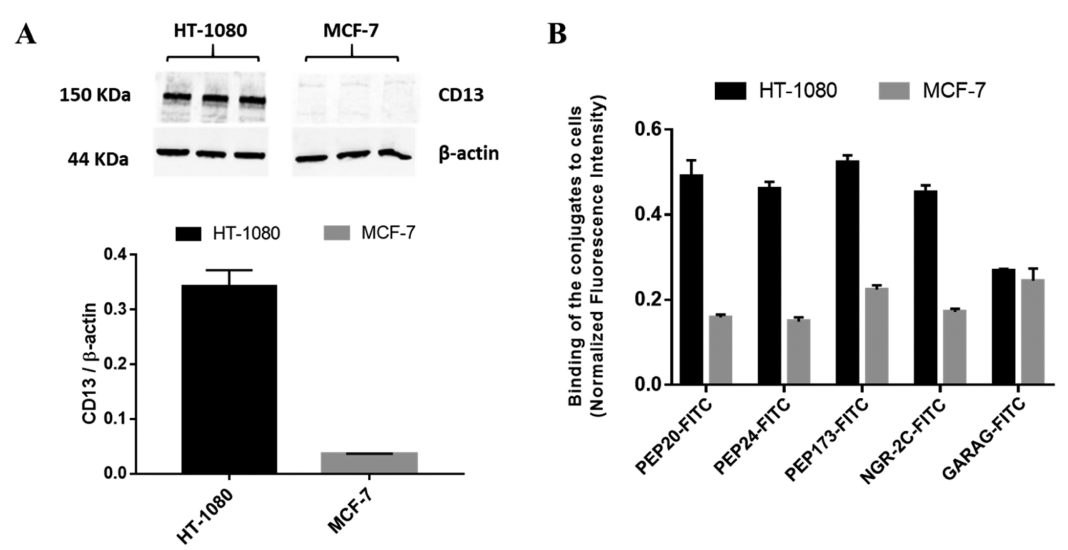

Figure 5. (A) CD13 expression levels in HT-1080 and MCF-7 cells (mean \pm SE, in triplicate) (B) binding of the peptide conjugates to HT-1080 and MCF-7 cells (mean \pm SE, in quadruplicate).

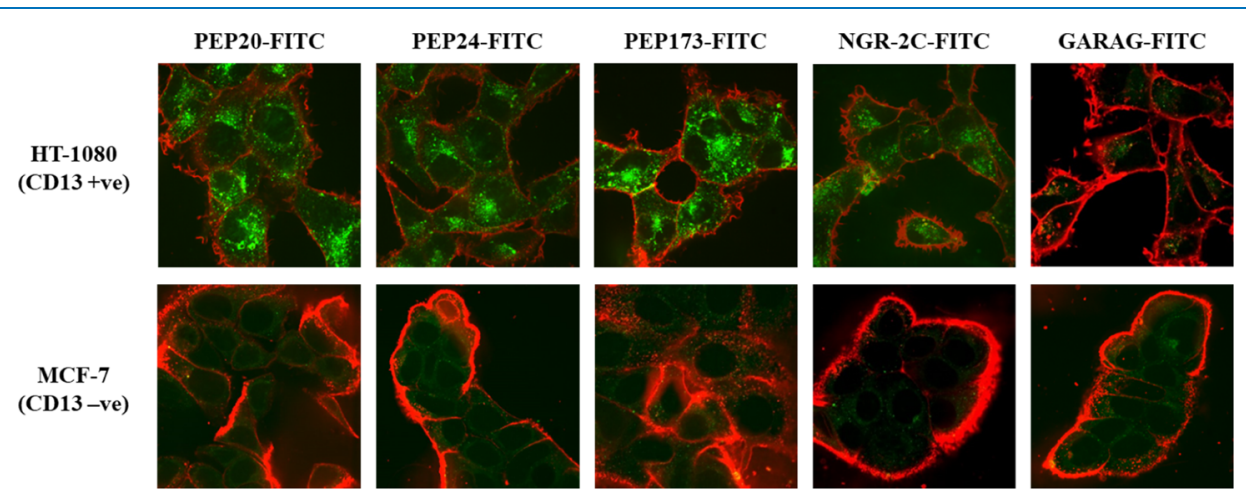

Figure 6. Evaluation of selectivity of the peptide conjugates. Green-FITC conjugated peptides, red-Alex Fluor plasma membrane dye.

intensity, HT-1080 cells showed 10-fold greater CD13 expression than MCF-7 cells. These data showed the suitability of using HT-1080 and MCF-7 cells as the CD13 positive and negative cell lines, respectively.

Cell Surface CD13 Binding of the Peptides. The ability of the peptides to recognize the cell surface CD13 receptor was evaluated by measuring the fluorescence intensity (cell number normalized) after incubating the FITC-conjugated peptides in CD13 positive HT-1080 cells and CD13 negative MCF-7 cells. In the cell binding assay, all the FITC conjugated peptides except the negative control conjugate (GARAG-FITC), showed significantly higher cell surface binding to CD13 positive HT-1080 cells as compared to the CD13 negative MCF-7 cells (Figure 5B). Additionally, the designed peptide (PEP20, PEP24, and PEP173) conjugates were found to exhibit slightly higher cell surface binding compared with NGR-2C conjugate in HT-1080 cells. These data suggested that the designed peptides could recognize and bind to the CD13 receptors on the cell surface.

Characterization of the Cell Internalization and Selectivity of the Peptides toward CD13. Cell internalization and selectivity of the designed peptides toward CD13 were evaluated in HT-1080 and MCF-7 cell lines using confocal microscopy. ${ }^{52,53}$ Confocal microscopy imaging was performed after incubating the cells with the FITC-conjugated peptides for $20 \mathrm{~min}$. In the HT-1080 cell images (Figure 6 upper panel), significant fluorescence was observed inside the cells and some fluorescence was detected on the cell surface for the designed peptides (PEP20-FITC, PEP24-FITC, and PEP173-FITC) and NGR-2C-FITC. The same molecules resulted in only background fluorescence in MCF-7 cell images (Figure 6 lower panel). FITC-labeled control peptide GARAG showed no binding to both the cell lines. These data demonstrated that the designed FITC-labeled peptides and the positive control NGR-2C-FITC bound and got internal- 

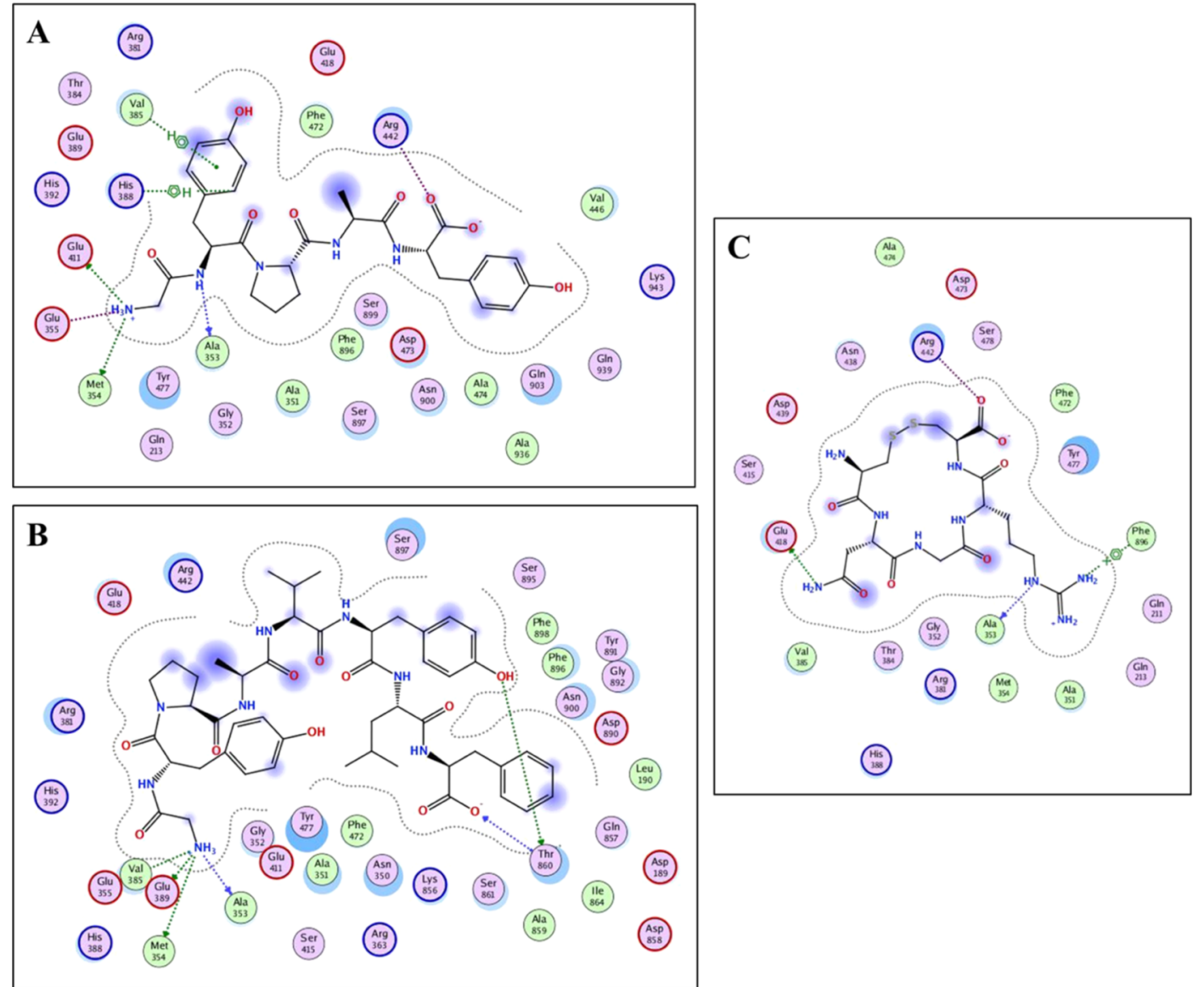

Figure 7. Ligand-receptor interaction diagrams. (A) Interaction of docked PEP20 at lowest energy conformation, (B) interaction of docked PEP173 at lowest energy conformation, and (C) interaction of docked NGR-2C at lowest energy conformation.

ized in the CD13 positive HT-1080 cells but not CD13 negative MCF-7 cells.

\section{DISCUSSION}

The structure-based design plays a crucial role in developing novel molecules/drugs. This approach to ligand design utilizes three-dimensional information of a target protein to improve recognition and discrimination by identifying favorable residue interactions. The first therapeutic peptide designed from crystal structure analysis was enfuvirtide, which received the US-FDA approval as an anti-HIV peptide in $2003 .{ }^{54}$ Foy et al. ${ }^{55}$ designed vaccines against EGFR by selecting different regions from the crystal structure of the protein. A VEGFR-3 targeted peptide ligand was developed by analyzing the crystal structure of the extracellular domain of VEGFR-3. ${ }^{56}$ Recently, Joshi et al. ${ }^{57}$ reported the design of a peptide that inhibits the enzymatic activity of CD13. The peptide was developed by a substrate-based approach where crystal structures of CD13 with different amino acids were solved to determine the structural basis of the substrate specificity. The structural insights into the protein-ligand interaction obtained from the crystal structures have culminated in a number of computational peptide design approaches. However, it is quite evident that the majority of these approaches are based on either sequence motifs or protein complexes. ${ }^{8}$ A rational design method based on the predicted interaction between target and ligand molecule will significantly speed up this development process.
In this study, a KS analysis of the protein-packing structure was used to rationally design peptide ligands with specificity for the CD13 active site. The method begins with mapping the target protein-binding site to characterize the amino acid packing arrangements in terms of three residue sockets on the target receptor that pack ligand knob residues-in this study the prototype receptor used was CD13. From the sockets identified as important for ligand binding on the surface of CD13, a set of knobs with high propensity interactions were selected. This set of amino acids enabled peptide sequences to be designed rationally by predicting the packing of the peptide ligand at the binding site. The peptides were screened in silico by docking programs to identify the best peptide candidates.

From the design approach, 412 potential peptide sequences were reduced to just 3 candidates. The three identified peptides showed selective binding to human CD13 receptor in vitro. In the enzymatic assay, the designed peptides exhibited higher CD13 catalysis inhibition than the CNGRC (C1-C5) peptide (NGR-2C). NGR-2C showed significantly reduced inhibition of CD13 enzymatic activity within $30 \mathrm{~min}$ (Figure $4 \mathrm{~A}$ ), suggestive of its unstable physicochemical characteristics at the assay condition. This phenomenon is not unexpected because the NGR-2C peptide has been reported to lose the CD13 binding ability rapidly through deamidation of the Asn residue. $^{58}$ The success of therapeutic peptides or peptide ligands depends on the delivery of their active form at the target site. The physicochemical stability of the peptides is largely influenced by the amino acid composition and sequences of the peptides. ${ }^{59-61}$ In our rational design method, 
peptides having potentially unstable amino acids or sequences can be excluded at the very beginning of the development works during peptide screening phase.

The three identified peptides [PEP173 (GYPAVYLF), PEP20 (GYPAY) and PEP24 (GFPAY)] showed 10-20 times higher binding affinity $\left(K_{\mathrm{i}}\right)$ toward hCD13 as compared to NGR-2C peptide $(773 \mu \mathrm{M})$ (Table 2). In other reported studies, $\mathrm{IC}_{50}$ of the NGR-2C peptide was $300-515 \mu \mathrm{M}$, and the $K_{\mathrm{i}}$ was $134 \mu \mathrm{M} .^{49,50}$ Unlike the fluorescence-based method used in the present study, those reported experiments used either L-leucine- $p$-nitroanilide or L-alanine- $p$-nitroanilide as the catalysis substrate, and the formation of $p$-nitroaniline product was measured by the absorbance at $405 \mathrm{~nm}$. The compositions of the assay buffer were also different in these studies. But generally, fluorescence-based detection techniques are more sensitive than the absorbance-based methods. ${ }^{62}$

The MOE ligand-receptor interaction analysis indicated that the higher binding affinity of the designed peptides as compared to the positive control NGR-2C peptide is possibly due to higher number of interactions with the receptor protein. While the number of interactions for the docked PEP20, 24, and 173 were 8,7 , and 10 , respectively, the docked NGR-2C peptide was seen to make five interactions with the hCD13 protein structure. The ligand-receptor interaction diagrams of PEP20, 173, and NGR-2C are presented in Figure 7. Ranking of the three peptides (PEP173, PEP20, and PEP24, respectively) according to their experimental binding affinities, $K_{\mathrm{i}}$ (38.8, 54.0, 74.3 $\mu \mathrm{M}$, respectively) was found to be in agreement with the ranking predicted by the MOE docking scores $(-16.2385,-13.9095,-11.9234 \mathrm{kcal} / \mathrm{mol}$, respectively) and number of interactions (10, 8, and 7, respectively). Additionally, as predicted by the AutoDock Vina (Figure 3 and Table 1), PEP20, 24, and 173 were found to bind to the catalytic active site of $\mathrm{CD} 13$ in the experimental steady-state enzyme kinetic assay (Figure 4B and Table 2). AutoDock Vina also accurately predicted the distant binding sites of the nonspecific control peptides [PEP293 (GYPAYVEF) and PEP308 (GFPAVYEF)] as experimentally confirmed by their observed noncompetitive inhibition mode in enzymatic assay (Figure 4B and Table 2). These findings suggest that the combination of multiple docking platforms in our design method could accurately predict the binding characteristics (affinity ranking and binding site) of the designed peptide ligands. Data from the cell binding and confocal microscopy assays (Figures 5 \& 6) further demonstrated that the designed peptides could recognize and selectively bind to the CD13 on the cell membrane.

The NGR-motif containing peptide ligand (i.e., CNGRC) for CD13 was first identified by an in vivo phage display selection study in a mouse model. ${ }^{20,21}$ Thus, the prototype target, CD13 receptor, allowed us to compare the performance of our rational peptide ligand design method with the structure-free design technique in terms of in vitro binding affinity and selectivity of the identified peptide ligands. A typical in vivo phage display screening starts with generating a large library of phage particles expressing a wide array of peptides on their surface. The size of the library can reach up to $10^{8}$ to $10^{9}$ different variants. ${ }^{63}$ The phage display library proceeds through a number of enrichment screening cycles, which involves binding, phage amplification, and plaque isolation. The final step is sequencing. Additional validation of the interaction may involve immunohistochemistry, real time PCR, bio-distribution, and homing inhibition studies. ${ }^{64}$
On the other hand, our design method rationally identified CD13 selective peptide ligands having better in vitro binding affinity with much less screening and experimental complexity.

\section{CONCLUSIONS}

In the present study, a rational peptide ligand design method based on the KS model of protein packing was developed and successfully employed to identify three novel peptide ligands for the model receptor, CD13. The identified peptides showed good selectivity and higher binding affinity toward the hCD 13 receptor in vitro as compared to the known peptide ligand CNGRC (C1-C5). Our study demonstrated the feasibility of the rational method to design novel peptide ligands. Most importantly, the rational method excluded the need of long experimental screening of a vast library of peptide sequences, and thus significantly reduces the time and resources traditionally employed to identify such molecules.

\section{ASSOCIATED CONTENT}

\section{Supporting Information}

The Supporting Information is available free of charge on the ACS Publications website at DOI: 10.1021/acsomega. 8 b03421.

KS propensity data, mass spectral data, \% purity of the synthesized molecules, and kinetic parameters of the steady-state CD13 enzyme kinetic assays (PDF)

\section{AUTHOR INFORMATION}

\section{Corresponding Author}

*E-mail: bjasti@pacific.edu.

ORCID $\odot$

Bhaskara Jasti: 0000-0002-6893-1237

Notes

The authors declare no competing financial interest.

\section{ACKNOWLEDGMENTS}

This work was partly supported by University of the Pacific Holmok Cancer Research Grant. We thank Dr. Mamoun Alhamadsheh, Arindom Pal, and Md Tariqul Haque Tuhin for their help in purifying the synthesized molecules. We also thank Dr. Roshanak Rahimian and Farjana Akther for helping in Western blot studies.

\section{ABBREVIATIONS}

CD13, cluster of differentiation 13; APN, aminopeptidase $\mathrm{N}$; ANG IV, angiotensin IV; PDB, protein data bank; MOE, molecular operating environment; DSSP, dictionary of secondary structure of protein; Ala-MCA, L-alanine 7-amido4-methylcoumarin; RP-HPLC, reversed phase high performance liquid chromatography; ESI-MS, electrospray ionization mass spectrometry

\section{REFERENCES}

(1) Ashley, E. A. Towards precision medicine. Nat. Rev. Genet. 2016, 17, 507-522.

(2) Muro, S. Challenges in design and characterization of ligandtargeted drug delivery systems. J. Controlled Release 2012, 164, 125137.

(3) Bae, Y. H.; Park, K. Targeted drug delivery to tumors: Myths, reality and possibility. J. Controlled Release 2011, 153, 198-205.

(4) Danhier, F.; Feron, O.; Préat, V. To exploit the tumor microenvironment: Passive and active tumor targeting of nanocarriers 
for anti-cancer drug delivery. J. Controlled Release 2010, 148, 135146.

(5) Zhang, X.-X.; Eden, H. S.; Chen, X. Peptides in cancer nanomedicine: drug carriers, targeting ligands and protease substrates. J. Controlled Release 2012, 159, 2-13.

(6) Gilad, Y.; Firer, M.; Gellerman, G. Recent Innovations in Peptide Based Targeted Drug Delivery to Cancer Cells. Biomedicines 2016, 4, 11.

(7) Fosgerau, K.; Hoffmann, T. Peptide therapeutics: current status and future directions. Drug Discovery Today 2015, 20, 122-128.

(8) Vanhee, P.; van der Sloot, A. M.; Verschueren, E.; Serrano, L.; Rousseau, F.; Schymkowitz, J. Computational design of peptide ligands. Trends Biotechnol. 2011, 29, 231-239.

(9) Smith, G. P.; Petrenko, V. A. Phage Display. Chem. Rev. 1997, 97, 391-410.

(10) Pasqualini, R.; Ruoslahti, E. Organ targeting in vivo using phage display peptide libraries. Nature 1996, 380, 364-366.

(11) Koivunen, E.; Arap, W.; Rajotte, D.; Lahdenranta, J.; Pasqualini, R. Identification of receptor ligands with phage display peptide libraries. J Nucl Med 1999, 40, 883-8.

(12) Campa, M. J.; Kuan, C.-T.; O’Connor-McCourt, M. D.; Bigner, D. D.; Patz, E. F., Jr. Design of a novel small peptide targeted against a tumor-specific receptor. Biochem. Biophys. Res. Commun. 2000, 275, 631-636.

(13) Park, B.-W.; Zhang, H.-T.; Wu, C.; Berezov, A.; Zhang, X.; Dua, R.; Wang, Q.; Kao, G.; O’Rourke, D. M.; Greene, M. I.; Murali, R. Rationally designed anti-HER2/neu peptide mimetic disables P185HER2/neu tyrosine kinases in vitro and in vivo. Nat. Biotechnol. 2000, 18, 194-198.

(14) Song, S.; Liu, D.; Peng, J.; Deng, H.; Guo, Y.; Xu, L. X.; Miller, A. D.; $\mathrm{Xu}, \mathrm{Y}$. Novel peptide ligand directs liposomes toward EGF-R high-expressing cancer cells in vitro and in vivo. FASEB J. 2009, 23, 1396-1404.

(15) Joo, H.; Chavan, A. G.; Phan, J.; Day, R.; Tsai, J. An Amino Acid Packing Code for $\alpha$-Helical Structure and Protein Design. J. Mol. Biol. 2012, 419, 234-254.

(16) Joo, H.; Tsai, J. An amino acid code for $\beta$-sheet packing structure. Proteins: Struct., Funct., Bioinf. 2014, 82, 2128-2140.

(17) Joo, H.; Chavan, A. G.; Fraga, K. J.; Tsai, J. An amino acid code for irregular and mixed protein packing. Proteins: Struct., Funct., Bioinf. 2015, 83, 2147-2161.

(18) Voronoi, G. F. Nouveles applications des paramétres continus à la théorie des formes quadratiques. J. Reine Angew. Math. 1908, 134, 198-287.

(19) Delauney, B. Sur la sphére vide. Bull. Acad. Sci USSR (VII). Classe Sci. Mat. Nat. 1934, 793-800.

(20) Arap, W.; Pasqualini, R.; Ruoslahti, E. Cancer treatment by targeted drug delivery to tumor vasculature in a mouse model. Science 1998, 279, 377-380.

(21) Pasqualini, R.; Koivunen, E.; Kain, R.; Lahdenranta, J.; Sakamoto, M.; Stryhn, A.; Ashmun, R. A.; Shapiro, L. H.; Arap, W.; Ruoslahti, E. Aminopeptidase $\mathrm{N}$ is a receptor for tumor-homing peptides and a target for inhibiting angiogenesis. Cancer Res. 2000, 60, $722-727$.

(22) Hashida, H.; Takabayashi, A.; Kanai, M.; Adachi, M.; Kondo, K.; Kohno, N.; Yamaoka, Y.; Miyake, M. Aminopeptidase N is involved in cell motility and angiogenesis: its clinical significance in human colon cancer. Gastroenterology 2002, 122, 376-386.

(23) Curnis, F.; Arrigoni, G.; Sacchi, A.; Fischetti, L.; Arap, W.; Pasqualini, R.; Corti, A. Differential binding of drugs containing the NGR motif to CD13 isoforms in tumor vessels, epithelia, and myeloid cells. Cancer Res 2002, 62, 867-74.

(24) Mina-Osorio, P. The moonlighting enzyme CD13: old and new functions to target. Trends Mol. Med. 2008, 14, 361-371.

(25) Wickström, M.; Larsson, R.; Nygren, P.; Gullbo, J. Aminopeptidase $\mathrm{N}$ (CD13) as a target for cancer chemotherapy. Cancer Sci. 2011, 102, 501-508.
(26) Abdollahi, A.; Folkman, J. Evading tumor evasion: current concepts and perspectives of anti-angiogenic cancer therapy. Drug Resist. Updates 2010, 13, 16-28.

(27) Corti, A.; Pastorino, F.; Curnis, F.; Arap, W.; Ponzoni, M.; Pasqualini, R. Targeted drug delivery and penetration into solid tumors. Med. Res. Rev. 2012, 32, 1078-1091.

(28) Liu, C.; Yang, Y.; Chen, L.; Lin, Y.-L.; Li, F. A unified mechanism for aminopeptidase $\mathrm{N}$-based tumor cell motility and tumor-homing therapy. J. Biol. Chem. 2014, 289, 34520-34529.

(29) Wong, A. H. M.; Zhou, D.; Rini, J. M. The X-ray crystal structure of human aminopeptidase $\mathrm{N}$ reveals a novel dimer and the basis for peptide processing. J. Biol. Chem. 2012, 287, 36804-36813.

(30) Pettersen, E. F.; Goddard, T. D.; Huang, C. C.; Couch, G. S.; Greenblatt, D. M.; Meng, E. C.; Ferrin, T. E. UCSF Chimera?A visualization system for exploratory research and analysis. J. Comput. Chem. 2004, 25, 1605-1612.

(31) Kabsch, W.; Sander, C. Dictionary of protein secondary structure: pattern recognition of hydrogen-bonded and geometrical features. Biopolymers 1983, 22, 2577-2637.

(32) Plaxco, K. W.; Simons, K. T.; Baker, D. Contact order, transition state placement and the refolding rates of single domain proteins 1 1Edited by P. E. Wright. J. Mol. Biol. 1998, 277, 985-994.

(33) http://tsailab.chem.pacific.edu/helix-socket-prediction.html (Accessed on March 19, 2016).

(34) Beck, A.; Bussat, M.-C.; Klinguer-Hamour, C.; Goetsch, L.; Aubry, J.-P.; Champion, T.; Julien, E.; Haeuw, J.-F.; Bonnefoy, J.-Y.; Corvaia, N. Stability and CTL activity of N-terminal glutamic acid containing peptides. J. Pept. Res. 2001, 57, 528-538.

(35) Middaugh, C. R.; Siahaan, T. J. Pharmaceutical Biotechnology. In Martin's Physical Pharmacy and Pharmaceutical Sciences: Physical Chemical and Biopharmaceutical Principles in the Pharmaceutical Sciences, 6th ed.; Sinko, P. J., Singh, Y., Eds.; Lippincott Williams \& Wilkins: Philadelphia, PA, 2011; pp 516-562.

(36) Li, S.; Schöneich, C.; Borchardt, R. T. Chemical instability of protein pharmaceuticals: Mechanisms of oxidation and strategies for stabilization. Biotechnol. Bioeng. 1995, 48, 490-500.

(37) Trott, O.; Olson, A. J. AutoDock Vina: improving the speed and accuracy of docking with a new scoring function, efficient optimization, and multithreading. J Comput Chem 2010, 31, 455-61.

(38) Hauser, A. S.; Windshügel, B. LEADS-PEP: A Benchmark Data Set for Assessment of Peptide Docking Performance. J. Chem. Inf. Model. 2016, 56, 188-200.

(39) http://vina.scripps.edu/manual.html (Accessed on September $11,2018)$.

(40) Chandrudu, S.; Simerska, P.; Toth, I. Chemical methods for peptide and protein production. Molecules 2013, 18, 4373-4388.

(41) Amblard, M.; Fehrentz, J.-A.; Martinez, J.; Subra, G. Fundamentals of modern peptide synthesis. Methods Mol. Biol. 2005, 298, 3-24.

(42) Mäde, V.; Els-Heindl, S.; Beck-Sickinger, A. G. Automated solid-phase peptide synthesis to obtain therapeutic peptides. Beilstein J. Org. Chem. 2014, 10, 1197-1212.

(43) Isidro-Llobet, A.; Álvarez, M.; Albericio, F. Amino acidprotecting groups. Chem. Rev. 2009, 109, 2455-2504.

(44) Kaiser, E.; Colescott, R. L.; Bossinger, C. D.; Cook, P. I. Color test for detection of free terminal amino groups in the solid-phase synthesis of peptides. Anal. Biochem. 1970, 34, 595-598.

(45) Kocienski, P. J.; Anizon, F.; Boyle, F. T.; Fisher, J. Synthesis and Characterisation of a Doxorubicin-CNGRC Peptide Conjugate that Targets Tumor Vasculature. Synthesis 2002, 18, 2733-2736.

(46) Chhabra, S. R.; Khan, A. N.; Bycroft, B. W. Versatile Dde-based primary amine linkers for solid phase synthesis. Tetrahedron Lett. 1998, 39, 3585-3588.

(47) Zheng, Y.; Ji, S.; Czerwinski, A.; Valenzuela, F.; Pennington, M.; Liu, S. FITC-Conjugated Cyclic RGD Peptides as Fluorescent Probes for Staining Integrin $\alpha \mathrm{v} \beta 3 / \alpha \mathrm{v} \beta 5$ in Tumor Tissues. Bioconjugate Chem. 2014, 25, 1925-1941.

(48) van Hensbergen, Y.; Broxterman, H. J.; Hanemaaijer, R.; Jorna, A. S.; van Lent, N. A.; Verheul, H. M.; Pinedo, H. M.; Hoekman, K. 
Soluble aminopeptidase N/CD13 in malignant and nonmalignant effusions and intratumoral fluid. Clin. Cancer Res. 2002, 8, 37473754.

(49) Plesniak, L. A.; Salzameda, B.; Hinderberger, H.; Regan, E.; Kahn, J.; Mills, S. A.; Teriete, P.; Yao, Y.; Jennings, P.; Marassi, F.; Adams, J. A. Structure and activity of CPNGRC: a modified CD13/ APN peptidic homing motif. Chem. Biol. Drug Des. 2010, 75, 551562.

(50) Curnis, F.; Fiocchi, M.; Sacchi, A.; Gori, A.; Gasparri, A.; Corti, A. NGR-tagged nano-gold: A new CD13-selective carrier for cytokine delivery to tumors. Nano Res. 2016, 9, 1393-1408.

(51) Chen, L.; Lin, Y.-L.; Peng, G.; Li, F. Structural basis for multifunctional roles of mammalian aminopeptidase N. Proc. Natl. Acad. Sci. U.S.A. 2012, 109, 17966-17971.

(52) Li, G.; Xing, Y.; Wang, J.; Conti, P. S.; Chen, K. Near-infrared fluorescence imaging of CD13 receptor expression using a novel Cy5.5-labeled dimeric NGR peptide. Amino Acids 2014, 46, 15471556.

(53) Liang, J.; Wu, W.-L.; Xu, X.-D.; Zhuo, R.-X.; Zhang, X.-Z. pH responsive micelle self-assembled from a new amphiphilic peptide as anti-tumor drug carrier. Colloids Surf., B 2014, 114, 398-403.

(54) Naider, F.; Anglister, J. Peptides in the treatment of AIDS. Curr. Opin. Struct. Biol. 2009, 19, 473-482.

(55) Foy, K. C.; Wygle, R. M.; Miller, M. J.; Overholser, J. P.; BekaiiSaab, T.; Kaumaya, P. T. P. Peptide vaccines and peptidomimetics of EGFR (HER-1) ligand binding domain inhibit cancer cell growth in vitro and in vivo. J. Immunol. 2013, 191, 217-227.

(56) Li, H. M.; Dong, Z. P.; Wang, Q. Y.; Liu, L. X.; Li, B. X.; Ma, X. N.; Lin, M. S.; Lu, T.; Wang, Y. De Novo Computational Design for Development of a Peptide Ligand Oriented to VEGFR-3 with High Affinity and Long Circulation. Mol. Pharm. 2017, 14, 2236-2244.

(57) Joshi, S.; Chen, L.; Winter, M. B.; Lin, Y. L.; Yang, Y.; Shapovalova, M.; Smith, P. M.; Liu, C.; Li, F.; LeBeau, A. M. The Rational Design of Therapeutic Peptides for Aminopeptidase N using a Substrate-Based Approach. Sci. Rep. 2017, 7, 1424.

(58) Curnis, F.; Cattaneo, A.; Longhi, R.; Sacchi, A.; Gasparri, A. M.; Pastorino, F.; Di Matteo, P.; Traversari, C.; Bachi, A.; Ponzoni, M.; Rizzardi, G.-P.; Corti, A. Critical role of flanking residues in NGR-toisoDGR transition and CD13/integrin receptor switching. J. Biol. Chem. 2010, 285, 9114-9123.

(59) Lai, M. C.; Topp, E. M. Solid-state chemical stability of proteins and peptides. J. Pharm. Sci. 1999, 88, 489-500.

(60) Pernot, M.; Vanderesse, R.; Frochot, C.; Guillemin, F.; BarberiHeyob, M. Stability of peptides and therapeutic success in cancer. Expert Opin. Drug Metab. Toxicol. 2011, 7, 793-802.

(61) Adessi, C.; Soto, C. Converting a peptide into a drug: strategies to improve stability and bioavailability. Curr. Med. Chem. 2002, 9, 963-978.

(62) Lakowicz, J. R. Fluorescence Sensing. In Principles of Fluorescence Spectroscopy, 3rd ed.; Springer: Boston, MA, 2006; pp 623-674.

(63) Kuzmicheva, G. A.; Belyavskaya, V. A. Peptide phage display in biotechnology and biomedicine. Biomed. Khim. 2016, 62, 481-495.

(64) Bábíčková, J.; Tóthová, L’; Boor, P.; Celec, P. In vivo phage display-a discovery tool in molecular biomedicine. Biotechnol. Adv. 2013, 31, 1247-1259. 